\title{
The heritable landscape of near-infrared and Raman spectroscopic measurements to improve lipid content in Atlantic salmon fillets
}

Gareth F. Difford ${ }^{1 *}$ (D) Siri S. Horn ${ }^{1}$, Katinka R. Dankel ${ }^{1}$, Bente Ruyter ${ }^{1}$, Binyam S. Dagnachew ${ }^{1}$, Borghild Hillestad², Anna K. Sonesson ${ }^{1}$ and Nils K. Afseth ${ }^{1}$

\begin{abstract}
Background: Product quality and production efficiency of Atlantic salmon are, to a large extent, influenced by the deposition and depletion of lipid reserves. Fillet lipid content is a heritable trait and is unfavourably correlated with growth, thus genetic management of fillet lipid content is needed for sustained genetic progress in these two traits. The laboratory-based reference method for recording fillet lipid content is highly accurate and precise but, at the same time, expensive, time-consuming, and destructive. Here, we test the use of rapid and cheaper vibrational spectroscopy methods, namely near-infrared (NIR) and Raman spectroscopy both as individual phenotypes and phenotypic predictors of lipid content in Atlantic salmon.

Results: Remarkably, 827 of the 1500 individual Raman variables (i.e. Raman shifts) of the Raman spectrum were significantly heritable (heritability $\left(\mathrm{h}^{2}\right)$ ranging from 0.15 to 0.65 ). Similarly, 407 of the 2696 NIR spectral landscape variables (i.e. wavelengths) were significantly heritable $\left(h^{2}=0.27-0.40\right)$. Both Raman and NIR spectral landscapes had significantly heritable regions, which are also informative in spectroscopic predictions of lipid content. Partial least square predicted lipid content using Raman and NIR spectra were highly concordant and highly genetically correlated with the lipid content values $\left(r_{g}=0.91-0.98\right)$ obtained with the reference method using Lin's concordance correlation coefficient (CCC $=0.63-0.90)$, and were significantly heritable $\left(h^{2}=0.52-0.67\right)$.

Conclusions: Both NIR and Raman spectral landscapes show substantial additive genetic variation and are highly genetically correlated with the reference method. These findings lay down the foundation for rapid spectroscopic measurement of lipid content in salmonid breeding programmes.
\end{abstract}

\section{Background}

Product quality and production efficiency of Atlantic salmon are, to a large extent, influenced by the deposition and depletion of lipid reserves. Atlantic salmon store the majority of their ingested energy as intra-muscular lipid,

*Correspondence: Gareth.difford@nofima.no

${ }^{1}$ Nofima, Norwegian Institute for Food, Fisheries and Aquaculture Research, NO-1433 Ås, Norway

Full list of author information is available at the end of the article which influences grading, processing, nutritional value, texture, colour, flavour and thereby consumer acceptance and market value of the fish [1-3]. Excess lipid is stored around the viscera and constitutes a high-cost slaughter waste [4]. The average lipid content in salmon fillet increases linearly with increasing dietary levels of crude fat up to a certain point after which residual reserves are stored around the viscera [5]. In spite of this, Atlantic salmon reared under the same conditions and on the same diet have markedly different fillet lipid contents,

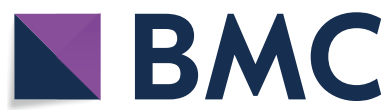

(c) The Author(s) 2021. This article is licensed under a Creative Commons Attribution 4.0 International License, which permits use, sharing, adaptation, distribution and reproduction in any medium or format, as long as you give appropriate credit to the original author(s) and the source, provide a link to the Creative Commons licence, and indicate if changes were made. The images or other third party material in this article are included in the article's Creative Commons licence, unless indicated otherwise in a credit line to the material. If material is not included in the article's Creative Commons licence and your intended use is not permitted by statutory regulation or exceeds the permitted use, you will need to obtain permission directly from the copyright holder. To view a copy of this licence, visit http://creativeco mmons.org/licenses/by/4.0/. The Creative Commons Public Domain Dedication waiver (http://creativecommons.org/publicdomain/ zero/1.0/) applies to the data made available in this article, unless otherwise stated in a credit line to the data. 
which often vary by more than 20 percentage points (Table 1).

Fillet lipid content is a heritable trait that is unfavourably correlated with growth [6-8]. Since growth is the most highly weighted trait in Atlantic salmon breeding programmes [9], selection indices and economic weighting of fillet lipid content are needed to achieve a genetic gain in growth without undesirable correlated responses in fillet lipid content [10], which can have knock-on effects on product quality and production efficiency. Conversely, evidence from other salmonid species indicates that selection for increased growth with restricted or controlled fillet lipid content improves feed efficiency, which is also a trait of high economic value [11].

In order to control for fillet lipid content in breeding programmes, it is necessary to measure this trait on thousands of related individuals under commercial conditions. Direct measurement of lipid traits is challenging because most measurement methods are carried out post-mortem, which requires sacrificing the fish, and in some cases the fillet. The gold standard method for measuring lipid content in salmon fillets is the chemical extraction of lipids using ethyl acetate, which was first described by [12]. As the gold standard or reference method, this method is the most accurate and precise measurement from which all other methods are benchmarked, and it is regarded as providing the 'True' value. However, it is time-consuming, costly, and is classified as a destructive method because both the fish and the fillet are sacrificed in the process. To the best of our knowledge, direct genetic evaluations using the reference method for measurement of fillet lipid have only recently been reported for Atlantic salmon [13].

Numerous alternative methods for recording fillet lipid content are under development, each with a unique set of advantages and disadvantages, and scope of applications. These can be broadly divided into: (1) non-destructive methods on live fish such as near-infrared (NIR) spectroscopy [14], Distell fat meter (Distell, UK), and low-field nuclear magnetic resonance (NMR) [15], and (2) fillet non-destructive methods such as computerised X-ray tomography $(\mathrm{CT})[16,17]$, PhotoFish, a commercialised camera system with controlled lighting (AKVA group, Norway), and online NIR spectroscopy [18].

Both NIR and Raman spectroscopy are techniques that fall within the family of vibrational spectroscopy methods. These techniques are rapid, require little to no sample preparation and can be automated, which make them well suited to the high-throughput phenotyping needs of modern breeding programmes and management operations. However, these two techniques rely on different mechanisms for inducing molecular vibrations and, thus, they provide different chemical data (see [19] for a comprehensive review). Whereas Raman spectroscopy typically provides higher resolution chemical information than NIR spectroscopy, NIR spectroscopy is the most routinely used method to record lipid contents in salmon. Among other reasons, this is related to the lack of

Table 1 Summary of heritability estimates for lipid content in Atlantic salmon and various measurement, sampling and available population descriptions in the literature

\begin{tabular}{|c|c|c|c|c|c|c|c|c|c|}
\hline Population & $\mathbf{N}$ & Harvest weight (kg) & Dietary fat (\%) & Muscle & Method & Lipid \% mean (SD) & Range (\%) & $h^{2}$ & Study \\
\hline Akvaforsk 1984 & 667 & $6.4 \pm 1.9$ & $17-18 \%$ & NQC & $C T$ & $16.7 \pm 2.7$ & $11.0-22.0^{b}$ & $0.30 \pm 0.09^{a}$ & {$[16]$} \\
\hline Akvaforsk 1985 & 604 & $6.9 \pm 1.8$ & $17-18 \%$ & NQC & CT & $14.5 \pm 2.4$ & $9.8-19.2^{b}$ & $0.30 \pm 0.09^{a}$ & {$[16]$} \\
\hline ASBDP & 472 & $6.7 \pm 1.5$ & $N R$ & RSGC & NIR & $15.9 \pm 2.0$ & $6.1-21.1$ & 0.19 & {$[7]$} \\
\hline MOWI 2002 & 136 & $3.9 \pm 0.1^{c}$ & $N R$ & NQC & NIR & $9.6 \pm 2.5$ & $2.8-14.7$ & $0.21 \pm 0.03^{a}$ & {$[48]$} \\
\hline MOWI 2003 & 19 & $5.3 \pm 0.3$ & $N R$ & NQC & NIR & $14.7 \pm 3.2$ & $7.6-20.0$ & $0.21 \pm 0.03^{\mathrm{a}}$ & {$[48]$} \\
\hline MOWI 2008 & 50 & $4.4 \pm 1.4$ & $27-37 \%$ & NQC & CE & $12.6 \pm 1.6$ & $9.5-15.6^{b}$ & NA & {$[49]$} \\
\hline MOWI $2008 \times$ WILD & 50 & $3.13 \pm 0.8$ & $27-37 \%$ & NQC & CE & $12.1 \pm 1.1$ & $10.0-14.2^{b}$ & NA & {$[49]$} \\
\hline WILD & 50 & $2.0 \pm 0.5$ & $27-37 \%$ & NQC & CE & $11.7 \pm 1.3$ & $9.2-14.3^{b}$ & NA & {$[49]$} \\
\hline AquaGen & 2428 & $N R$ & $31-35 \%$ & Fillet & NIR & NR & $N R$ & 0.28 & {$[50]$} \\
\hline Landcatch 2004 & 1682 & $1.98 \pm 0.8$ & $N R$ & RS8 & DFM & $13.5 \pm 4.3$ & $5.5-21.8^{b}$ & $0.28 \pm 0.05$ & {$[8]$} \\
\hline Landcatch 2002 & 1697 & $2.57 \pm 0.6$ & $N R$ & RS8 & DFM & $12.2 \pm 5.6$ & $1.3-23.2$ & $0.18 \pm 0.03$ & {$[51]$} \\
\hline SalmoBreed 2001 & 2634 & $3.16 \pm 0.7$ & $N R$ & NQC & NR & $12.6 \pm 1.4$ & $5.4-17.1$ & $N R$ & {$[52]$} \\
\hline SalmoBreed 2014 & 668 & $3.6 \pm 0.9$ & $36 \%$ & NQC & CE & $19.1 \pm 3.4$ & $5.5-27.7$ & $0.46 \pm 0.10$ & [13] \\
\hline
\end{tabular}

$N$ number of fish, NQC Norwegian quality cut, RSGC right side behind gill cover, RS8 8 random samples over entire body, CT computerised X-ray tomography, NIR near infrared, CEchemical extraction, DFM Distell fat meter, $N R$ not reported, NA not applicable. $h^{2}$ heritability

a Indicate $h^{2}$ estimates from joint year classes

b Indicates range estimated from mean $\pm 1.96 *$ standard deviation

c Indicates gutted weight 
appropriate sampling tools for collecting representative Raman spectra of heterogeneous samples [19]. NIR and Raman spectroscopy rely on calibration equations that are generated with the reference method that is measured on $\sim 50$ to 100 salmon fillets. Then, the accuracy of the calibration equations is tested through prediction on validation sets. Previous studies on lipid content estimation using NIR spectroscopy suggest that estimation errors range from 0.5 to $1.0 \%$ [20]. For Raman spectroscopy, very few studies have been reported in the literature. Wold et al. [21] used a spherical lens probe for efficient Raman sampling, and obtained good results for the prediction of fat contents in ground salmon with a cross-validation correlation $\left(\mathrm{R}_{\mathrm{CV}}\right)$ of 0.95 and a root mean squared error of cross-validation (RMSECV) of $1.6 \%$. These values suggest that lipid contents in Atlantic salmon fillet that are obtained with the reference method and those that are predicted by using Raman or NIR vibrational spectroscopy should be phenotypically nearly equivalent. Remarkably, the existence or lack of genetic equivalence between the 'True' lipid content and that obtained with alternative methods has not been established, although fillet lipid content is included in the selection programmes of multiple breeding populations (Table 1). Furthermore, the phenotypic agreement or concordance between NIR and Raman predicted lipid phenotypes and lipid contents recorded with the reference method has not been reported for large-scale genetic cohorts. Since NIR and Raman predicted phenotypes are linear combinations of thousands of measured spectra which can themselves be considered as phenotypes, it follows that the individual spectra maybe be heritable and genetically correlated with true lipid content. Thus, developing an optimal strategy for using NIR and Raman spectroscopy measurements in genetic evaluations requires estimation of heritabilities at individual NIR wavelengths and Raman shifts, and of their phenotypic and genetic relationships with the reference value for fillet lipid contents. Therefore, the objectives of our study were to (1) estimate genetic parameters for NIR and Raman spectroscopy measurements in Atlantic salmon fillet, and (2) estimate genetic parameters between the reference fillet lipid content and predicted lipid content using NIR and Raman phenotypes and their components.

\section{Methods}

\section{Fish population}

As part of commercial breeding operations, SalmoBreed AS (today named Benchmark Genetics Norway AS) created 194 full-sibling families using 92 sires and 194 dams for the 2014 year-class. Details on animal husbandry and feeding are in [13, 22]. All fish were reared under the same conditions. Briefly, families were reared separately until a mean weight of $113.1 \mathrm{~g}$, and the fish were transferred to sea cages after smoltification. After being fed on a high fish oil content broodstock feed (LifePhase Vitalis, Skretting AS, Norway), at a mean weight of $3605 \mathrm{~g}$ and approximately 12 months at sea, 668 fish were fasted for 13 to 14 days and then harvested and filleted. Fish were screened for sexual maturation and those that were sexually mature were excluded from further analysis (31 males), and external deformities and individual filleting were also recorded. The pedigree included 1685 animals and included four generations of information on direct ancestors of the fish included in our study.

\section{Trait recording}

Four lipid traits were recorded on each individual and are described in chronological order as follows: (1) reference method lipid content $\left(\operatorname{Lipid}_{\text {True }}\right)$, (2) commercial NIR system lipid content (Lipid ${ }_{\text {FieldNIR }}$ ), (3) laboratorybased NIR system $\left(\operatorname{Lipid}_{\text {NIR }}\right)$, and (4) laboratory-based Raman system ( Lipid $\left._{\text {Raman }}\right)$ lipid contents. At slaughter, the sex of each individual was determined by visual inspection of the gonads and recorded. NIR absorbance spectra were recorded immediately after slaughter on fillets (non-destructively) using a commercial NIR imaging scanner (QVision500, Tomra Sorting Solutions, Leuven, Belgium), which immediately gives the predicted lipid content of the fillet in the field $\left(\operatorname{Lipid}_{\text {FieldNIR }}\right)$ [23]. The NIR absorbance spectra and the prediction equation used to predict lipid content are proprietary and not available to researchers. Muscle samples were taken from the Norwegian Quality Cut (NQC), frozen and stored at $-20{ }^{\circ} \mathrm{C}$. Total lipids were extracted from homogenized NQC muscle samples from each fish, and lipid content was determined in $\mathrm{g}$ of lipid per $100 \mathrm{~g}$ of muscle tissue calculated according to the method described by [12] $\left(\operatorname{Lipid}_{\text {True }}\right)$. Then, homogenized muscle samples were recorded for laboratory-based Raman and NIR spectroscopy analysis as described below.

Raman spectra were obtained using a Kaiser Raman$\mathrm{RXN}^{\mathrm{TM}}$ Multi-channel Raman analyzer (Kaiser Optical Systems, Inc., Ann Arbor, MI, USA) with a spectral resolution of $5 \mathrm{~cm}^{-1}$. The spectrometer was equipped with a $785 \mathrm{~nm}$ laser and PhAT probe with a laser spot size diameter of $6 \mathrm{~mm}$. The spectra were recorded with a laser power set to $400 \mathrm{~mW}$ within the range of 300 to $1890 \mathrm{~cm}^{-1}$ with $0.3-\mathrm{cm}^{-1}$ intervals. Each spectrum was an average of four $15 \mathrm{~s}$ accumulations. All homogenized muscle samples were randomized, and three replicate measurements were obtained for each sample. The instrument was controlled using the iC Raman version X software (Mettler Toledo, Greifensee, Switzerland). For pre-processing, extended multiplicative signal correction (EMSC) with a sixth order polynomial extension was 
used [24]. In short, the spectra were trimmed within the 500 to $1800 \mathrm{~cm}^{-1}$ range, and EMSC was performed on all replicate spectra. The mean spectrum of all the replicate spectra was subjected to polynomial baseline correction (fourth order) and used as a reference in EMSC. The average Raman spectrum for each sample was subsequently calculated and used for further analysis.

Diffuse reflectance near-infrared spectra of homogenized salmon samples were obtained using the FOSS NIRSystems XDS Rapid Content ${ }^{\mathrm{TM}}$ Analyzer (FOSS Analytical A/S, Hillerød, Denmark). NIR spectra were obtained in reflectance mode with 32 scans per spectrum. Homogenised samples were randomised and measured in triplicates, with the average spectrum used for further analysis. An internal ceramic standard was used as a reference. The spectral range was from 400 to $2500 \mathrm{~nm}$ with $0.5 \mathrm{~nm}$ increments. In order to follow Beer's law, the NIR spectra were transformed from reflectance $(\mathrm{R})$ units into absorbance $\left(\mathrm{A}=\log _{10}(1 / \mathrm{R})\right)$ and standard normal variate (SNV) pre-processed units. For subsequent analyses, the spectral range from 1150 to $2500 \mathrm{~nm}$ was used since it covers the main information related to lipids in the NIR spectrum [25].

\section{Statistical analysis}

Predictions of lipid content phenotypes from Raman and NIR spectra were performed independently by partial least squares regression (PLSR) using the PLS package in $R$ [26]. After merging all the data, 523 samples were available with data from all analytical sources used in the study (i.e. phenotypic and spectroscopic data). On average, in the remaining dataset each sire had five offspring. The Raman and NIR data were divided into a random calibration set of 60 individuals in order to keep the calibration size consistent with commercial applications and a validation set of 463 individuals. In order to avoid over- or underfitting in the final PLSR model, the optimal number of PLSR components for the final PLSR model was chosen based on the lowest root mean squared error of cross-validation (RMSECV) using 10 random sets of 'leave one out' cross-validation within the calibration set. For the Raman data, the optimal number of components was 4 , and these were used to predict lipid content in the full validation set, resulting in a RMSECV of $0.97 \%$ for the calibration set and $1.34 \%$ for the validation set. The coefficient of determination $\left(R^{2}\right)$ for the calibration and validation sets were 0.92 , and 0.81 , respectively. For the NIR spectra, the optimal number of components was 7 , and these were used to predict lipid content in the validation set, resulting in a RMSECV of $1.04 \%$ and $1.32 \%$ in the calibration and validation sets, respectively. The $\mathrm{R}^{2}$ for the calibration and validation sets were 0.93 and 0.84 , respectively. Raman $\left(\operatorname{Lipid}_{\text {Raman }}\right)$ and NIR ( $\operatorname{Lipid}_{\text {NIR }}$ ) predicted lipid contents were used as phenotypes in the genetic analyses presented below.

The overall phenotypic agreement between predicted fillet lipid contents and true lipid content was assessed by Lin's concordance correlation coefficient (CCC) [27].

Variance components were estimated by applying univariate animal models using average information criterion restricted maximum likelihood models in DMU version 6 [28]:

$$
\mathbf{y}=\mathbf{X b}+\mathbf{Z a}+\mathbf{e}
$$

where $\mathbf{y}$ is the vector of phenotypes for individual $i=1,2,3 \ldots n$; i.e. 1300 phenotypes for Raman shift values, 2300 phenotypes for NIR absorbance values, and the four lipid content phenotypes $\left(\operatorname{Lipid}_{\text {True }}, \operatorname{Lipid}_{\text {FieldNIR }}\right.$, Lipid $_{\text {NIR }}$, and Lipid Raman $)$. The incidence matrix $\mathbf{X}$ links phenotype $\mathbf{y}$ to the fixed effect of sex (two levels, male and female). Potential fixed effects of filleter (7 levels) and spinal deformity ( 2 levels) were found to be non-significant $(\alpha<0.05)$ and thus were not included in subsequent analyses. $\mathbf{a}$ is the vector of genetic effects assumed to be normally distributed $\mathbf{a} \sim \mathrm{N}\left(0, \mathbf{A} \sigma_{\mathrm{a}}^{2}\right)$, where $\mathbf{A}$ is the pedigree derived numerator relationship matrix and $\sigma_{\mathrm{a}}^{2}$ the additive genetic variance. $\mathbf{Z}$ is the incidence matrix that links observations to genetic effects, and $\mathbf{e}$ is the vector of random residuals and follows a normal distribution $\mathbf{e} \sim \mathrm{N}\left(0, \mathbf{I} \sigma_{\mathrm{e}}^{2}\right)$, where $\mathbf{I}$ is the identity matrix and $\sigma_{\mathrm{e}}^{2}$ the residual variance. Heritability $\left(h^{2}\right)$ estimates were calculated as the ratio of additive genetic variance to total phenotypic variance $\sigma_{\mathrm{a}}^{2} /\left(\sigma_{\mathrm{a}}^{2}+\sigma_{\mathrm{e}}^{2}\right)$ and their standard errors by using a Taylor series approximation. Statistical $p$ values were computed for each heritability estimate following $t$ distributions and then adjusted for false discovery rate (FDR) using the Benjamini-Hochberg procedure [29].

Bivariate animal models were run pairwise between the four lipid content traits and followed the same form as Eq. (1) assuming the following additive genetic and residual covariance structures:

$$
\begin{aligned}
& \operatorname{var}\left[\begin{array}{c}
\mathbf{a}_{j} \\
\mathbf{a}_{\text {True }}
\end{array}\right]=\left[\begin{array}{cc}
\mathbf{A} \sigma_{a j}^{2} & \mathbf{A} \sigma_{\text {ajaTrue }} \\
\mathbf{A} \sigma_{\text {aTrueaj }} & \mathbf{A} \sigma_{\text {aTrue }}^{2}
\end{array}\right] \\
& \operatorname{var}(\mathbf{e})=R=\left[\begin{array}{cc}
\mathbf{I} \sigma_{e j}^{2} & \mathbf{I} \sigma_{\text {ejeTrue }} \\
\mathbf{I} \sigma_{\text {eTrueej }} & \mathbf{I} \sigma_{\text {eTrue }}^{2}
\end{array}\right],
\end{aligned}
$$

where $j$ indicates the alternative lipid content traits $\left(\operatorname{Lipid}_{\text {NIRField }}\right.$ Lipid $_{\text {NIR }}$ and Lipid $\left.{ }_{\text {Raman }}\right)$ and True indicates the trait $\operatorname{Lipid}_{\text {True }}$ obtained by the reference method. Genetic and phenotypic correlations were estimated as the covariance divided by the square root of the product 
of two variances for the additive genetic and phenotypic (co)variances, respectively. The genetic correlation of individual Raman shifts and NIR wavelengths with Lipid $_{\text {True }}$, was estimated as the correlation between their respective EBV from Eq. (1) corrected by their respective reliabilities using the Calo method [30,31].

\section{Results}

\section{Descriptive statistics}

The descriptive statistics for the lipid content traits are in Table 2. The means of the alternative lipid traits ranged from 18.9 to $21.0 \%$ and were not significantly statistically different from $\operatorname{Lipid}_{\text {True }} 19.07 \%(\mathrm{P}>0.05)$. All lipid phenotypes were substantially heritable $\left(h^{2}=0.51-0.67\right)$. The phenotypic correlations deviated from $1(0.80-0.92)$ and the concordance correlation coefficients ranged from 0.63 to 0.92 , and all genetic correlations were higher than 0.90 (ranging from 0.91 to 0.98 ) (Table 2).

\section{Heritability estimates}

The heritability estimates for individual Raman shifts from 500 to $1800 \mathrm{~cm}^{-1}$ are presented in Fig. 1, and the highest $h^{2}$ reached 0.65. In total, 827 Raman shifts were significantly heritable at $\alpha=0.05$ after correction for a false discovery rate (FDR) of $10 \%$. Previous studies on the prediction of lipid content of salmon fillet and control

Table 2 Descriptive statistics and genetic and phenotypic parameters for lipid content traits recorded on 523 Atlantic salmon

\begin{tabular}{|c|c|c|c|c|c|c|c|}
\hline \multirow[t]{2}{*}{ Traits } & \multicolumn{4}{|c|}{ Descriptive statistics } & \multicolumn{3}{|c|}{ Correlations with Lipid } \\
\hline & Mean \pm SD & CV \% & Min_Max & $h^{2} \pm \mathrm{SE}$ & Phenotypic & Genetic & $\mathrm{CCC}$ \\
\hline Lipid $_{\text {True }}$ & $19.07 \pm 3.16$ & 17 & $5.45-26.9$ & $0.51 \pm 0.11$ & & & \\
\hline Lipid $_{\text {FieldNIR }}$ & $21.0 \pm 2.42$ & 12 & $10.4-28.3$ & $0.67 \pm 0.12$ & $0.80 \pm 0.03$ & $0.91 \pm 0.04$ & 0.63 \\
\hline Lipid $_{N I R}$ & $18.9 \pm 2.90$ & 14 & $5.6-26.8$ & $0.60 \pm 0.10$ & $0.80 \pm 0.03$ & $0.93 \pm 0.03$ & 0.68 \\
\hline Lipid $_{\text {Raman }}$ & $19.0 \pm 2.84$ & 15 & $0.6-24.0$ & $0.52 \pm 0.12$ & $0.92 \pm 0.02$ & $0.98 \pm 0.01$ & 0.92 \\
\hline
\end{tabular}

SD standard deviation, CV coefficient of variation, $h^{2}$ heritability, CCC Lin's concordance correlation coefficient

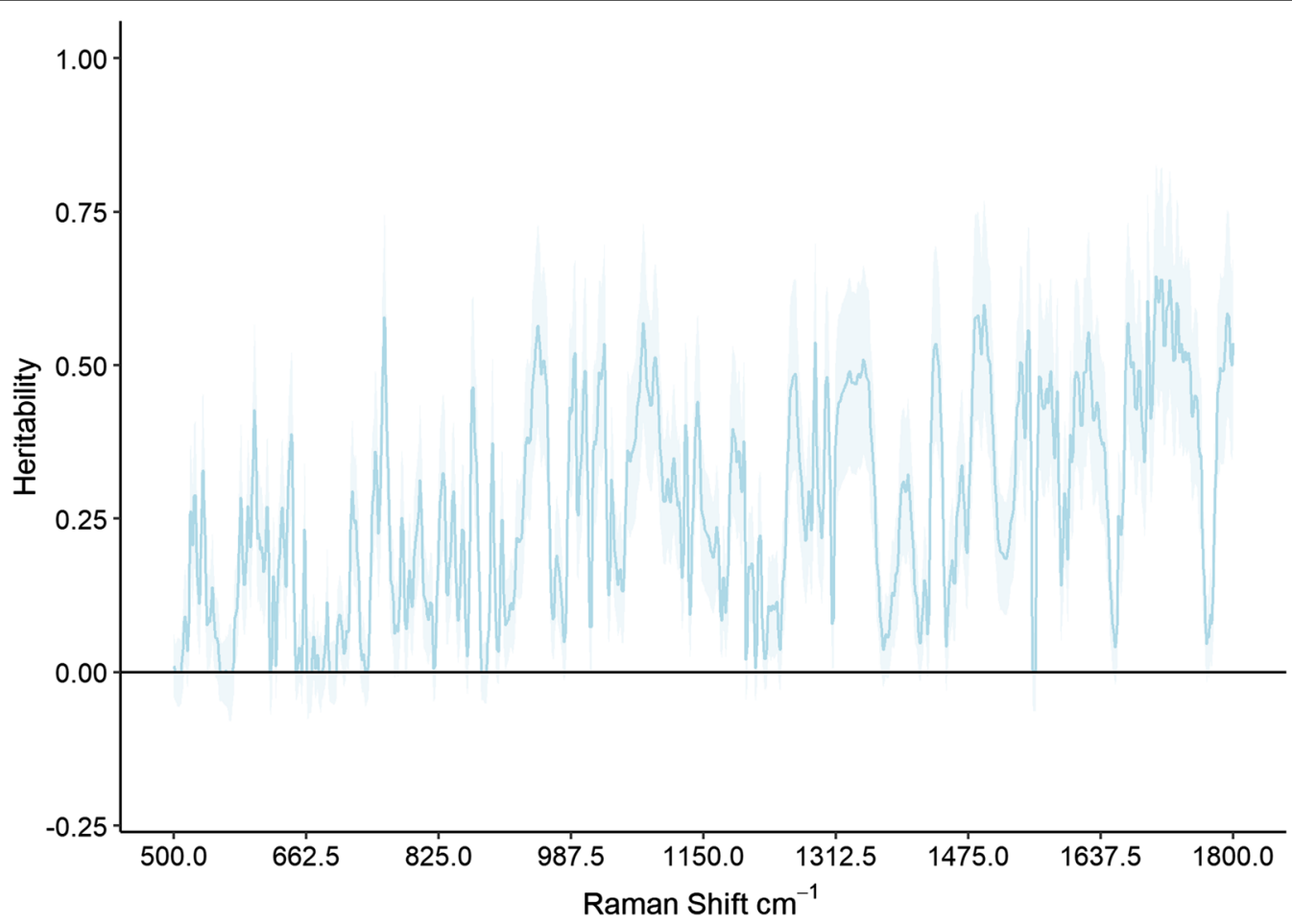

Fig. 1 Heritability $\left(h^{2}\right)$ blue solid line with standard errors (light blue shading) for 1300 individual wavenumbers from the Raman shift region from 500 to $1800 \mathrm{~cm}^{-1}$ in Atlantic salmon fillets. Solid black line denotes the origin (0) 
mock samples with known varying amounts of water and lipid involved eight spectral bands [25, 32, 33]. Several heritability estimates were significant within these spectral bands, i.e. for the: (1) C-C stretch $1064-1068 \mathrm{~cm}^{-1}$ with $h^{2}=0.39$; (2) C-C stretch $1076-1081 \mathrm{~cm}^{-1}$ with $h^{2}$ $=0.52$; (3) $\mathrm{C}-\mathrm{C}$ stretch $1126-1130 \mathrm{~cm}^{-1}$ with $h^{2}=0.35$; (4) symmetric $=\mathrm{C}-\mathrm{H}$ rocking $1263-1267 \mathrm{~cm}^{-1}$ with $h^{2}$ $=0.44$; (5) $\mathrm{CH}_{2}$ twist $1300-1305 \mathrm{~cm}^{-1}$ with $h^{2}=0.43$; (6) $\mathrm{CH}_{2}$ scissoring $1440-1445 \mathrm{~cm}^{-1}$ with $h^{2}=0.38$; (7) cis $\mathrm{C}=\mathrm{C}$ stretch and amide I $1656-1660 \mathrm{~cm}^{-1}$ with $h^{2}=$ 0.25 ; and (8) $\mathrm{C}=\mathrm{O}$ stretch $1744-1749 \mathrm{~cm}^{-1}$ with $h^{2}=$ 0.39 (See Additional file 1: Table S1).

The heritability estimates for individual NIR wavelengths between 1150 and $2500 \mathrm{~nm}$ are presented in Fig. 2. The highest $h^{2}$ was moderate at 0.40 . In total, 407 individual wavelengths were significantly heritable at $\alpha=0.05$ after correction for a FDR of $10 \%$. Based on the well characterised associations between NIR spectral bands and different chemical bonds, and on control mock samples of varying lipid and water content, it was possible to screen NIR regions that are known to be relevant for predicting lipid content [25]. Several spectral bands associated with chemical bonds that are informative for lipid content were also significantly heritable; for example, the first asymmetric and symmetric $\mathrm{C}-\mathrm{H}$ stretch overtones at $1715 \mathrm{~nm}\left(h^{2}=0.38\right)$ and $1760 \mathrm{~nm}\left(h^{2}=\right.$
0.29 ), and the combination bands of the $\mathrm{C}-\mathrm{H}$ stretch and deformation at $2310 \mathrm{~nm}\left(h^{2}=0.40\right)$ and $2350 \mathrm{~nm}\left(h^{2}\right.$ $=0.39$ ). However, no significant genetic variation was observed for the combination bands for cis unsaturation in carbon chains at $2140 \mathrm{~nm}$ and $2180 \mathrm{~nm}$. The first $\mathrm{O}-\mathrm{H}$ overtone at $1450 \mathrm{~nm}$, the $\mathrm{O}-\mathrm{H}$ stretch $1930 \mathrm{~nm}$ and the deformation at $1190 \mathrm{~nm}$ associated with water content were not significantly heritable $\left(h^{2}=0.00-0.13\right)$ (see Additional file 2: Table S2, Additional file 3: Table S3 for Raman shift EBV and Additional file 4: Table S4 for NIR EBV).

\section{Correlations with lipid content}

The genetic and phenotypic correlations of each Raman shift with Lipid $_{\text {True }}$ content are shown on Fig. 3. The patterns of phenotypic and genetic correlations were consistent in sign and magnitude across the Raman shift range. The estimated genetic correla-

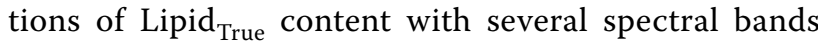
associated with various chemical bonds in lipids were strong and positive; for example, with the $\mathrm{C}-\mathrm{C}$ stretch at $1064-1068 \mathrm{~cm}^{-1}\left(r_{\mathrm{g}}=0.90\right)$, the $\mathrm{C}-\mathrm{C}$ stretch at $1076-1081 \mathrm{~cm}^{-1}\left(r_{\mathrm{g}}=0.73\right)$, the symmetric $=\mathrm{C}-\mathrm{H}$ rocking at $1263-1267 \mathrm{~cm}^{-1}\left(r_{\mathrm{g}}=0.77\right)$, the $\mathrm{CH}_{2}$ twist at $1300-1305 \mathrm{~cm}^{-1}\left(r_{\mathrm{g}}=0.85\right)$, the $\mathrm{CH}_{2}$ scissoring at $1440-1445 \mathrm{~cm}^{-1}\left(r_{\mathrm{g}}=0.80\right)$ and the $\mathrm{C}=\mathrm{O}$ stretch at

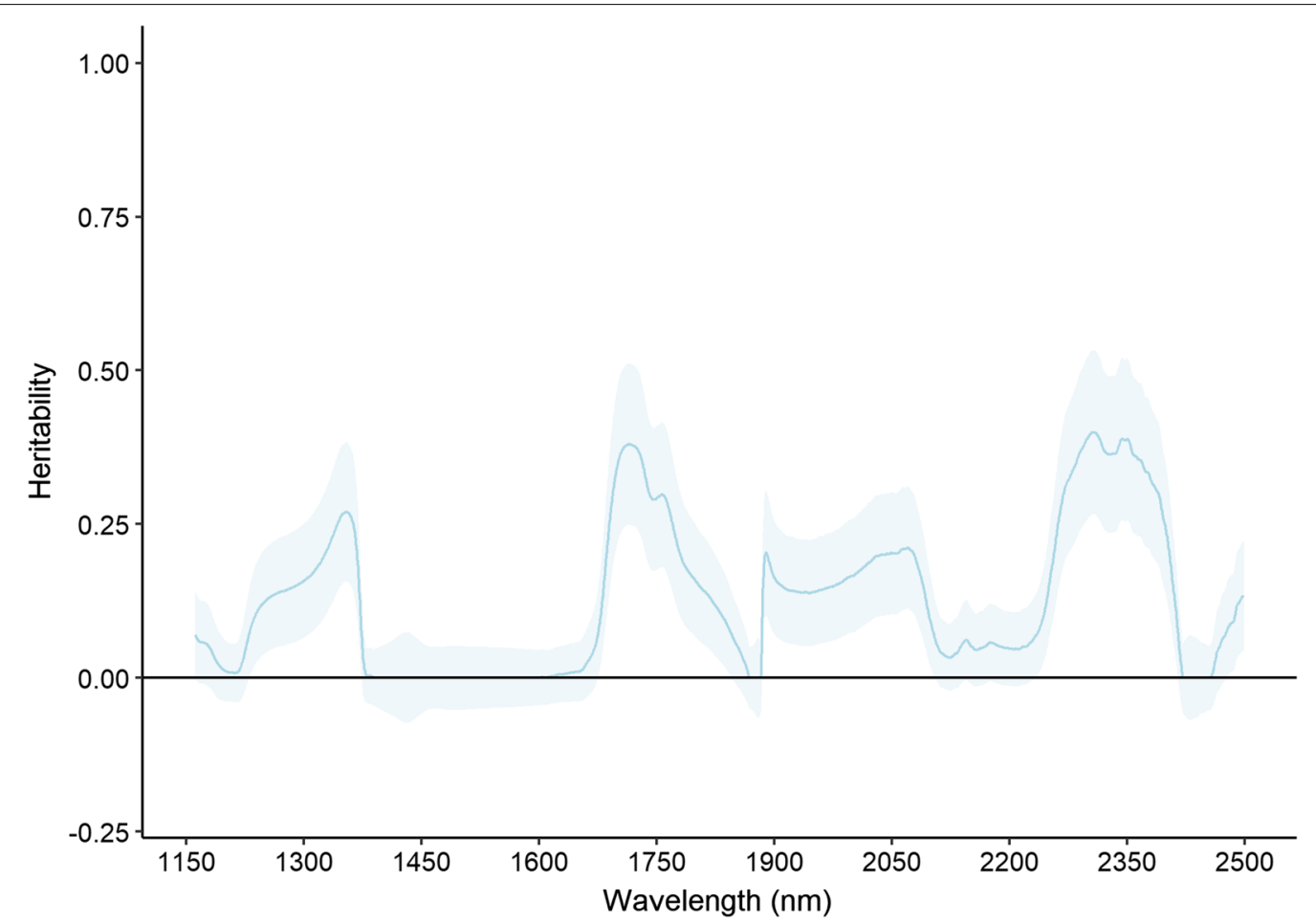

Fig. 2 Heritability $\left(h^{2}\right)$ blue solid line with standard errors (light blue shading) for 2700 individual wavenumbers from the NIR wavelength region from 1150 to $2500 \mathrm{~cm}^{-1}$ in Atlantic salmon fillets. Solid black line denotes the origin (0) 


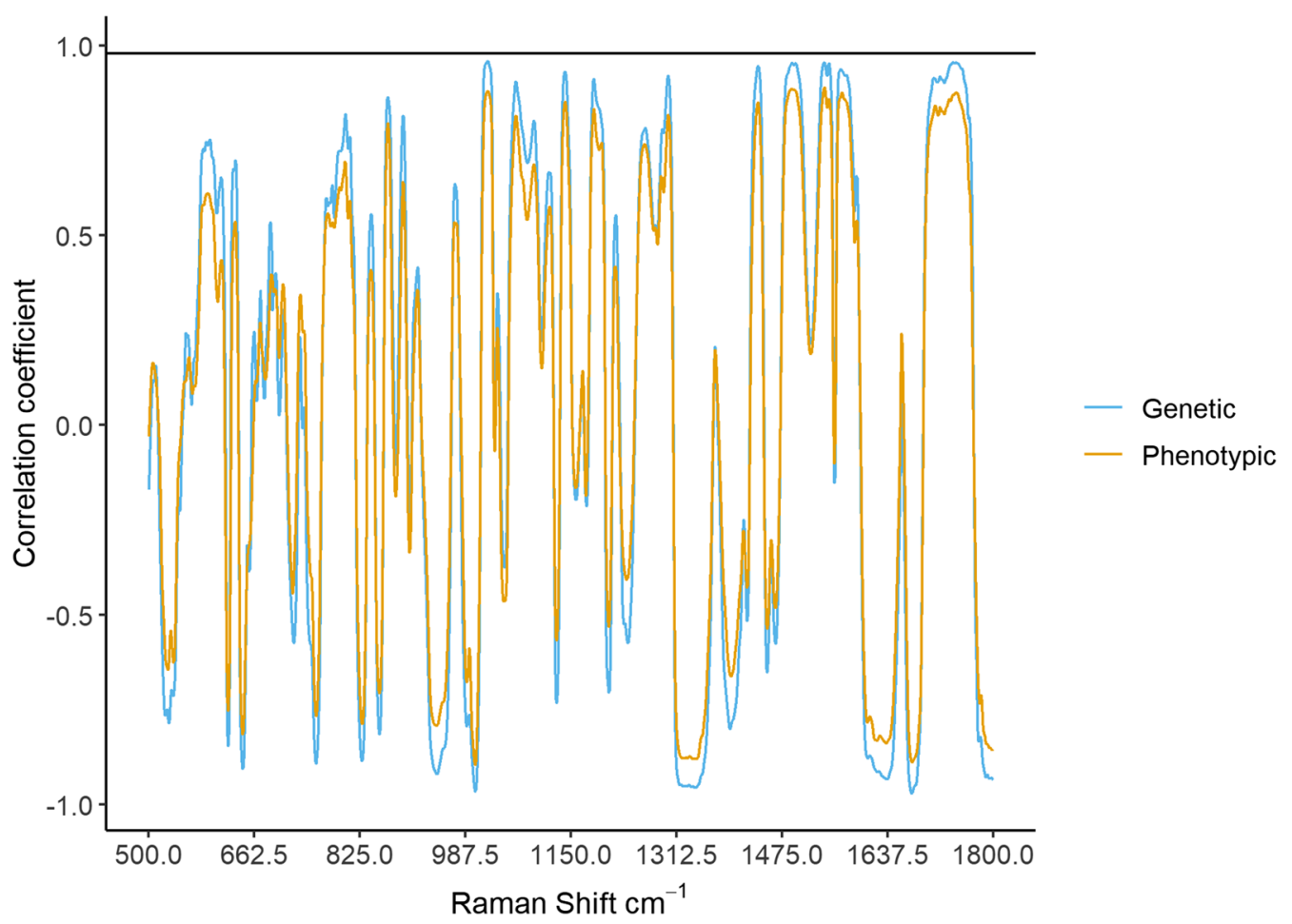

Fig. 3 Genetic (light blue) and phenotypic (yellow) correlations between each individual Raman shift and lipid content. The genetic correlation between Raman predicted lipid content and true lipid content indicated by the solid black line

$1744-1749 \mathrm{~cm}^{-1}\left(r_{\mathrm{g}}=0.95\right)$. The $\mathrm{C}-\mathrm{C}$ stretch at $1126-$ $1130 \mathrm{~cm}^{-1}$ had a strong negative genetic correlation with Lipid ${ }_{\text {True }}$ content $\left(r_{\mathrm{g}}=-0.69\right)$ and the cis $\mathrm{C}=\mathrm{C}$ stretch and amide I at $1656-1660 \mathrm{~cm}^{-1}$ had weak nonsignificant correlations with LipidTrue content $\left(r_{\mathrm{g}}=\right.$ -0.06 and $r_{\mathrm{p}}=0.09$ ) (see Additional file 5: Table S5 for Raman shift correlations).

The genetic and phenotypic correlations of each NIR wavelength with Lipid ${ }_{\text {True }}$ content and Lipid ${ }_{\text {NIR }}$ are presented in Fig. 4. The pattern of phenotypic and genetic correlations was consistent in sign and magnitude across the NIR wavelength range. The estimated genetic correlations of Lipid ${ }_{\text {True }}$ content and Lipid ${ }_{\text {NIR }}$ with several spectral bands associated with various chemical bonds in lipids were strong and positive; for example, with the first asymmetric and symmetric $\mathrm{C}-\mathrm{H}$ stretch overtones at $1715 \mathrm{~nm}\left(r_{\mathrm{g}}=0.92\right)$ and $1760 \mathrm{~nm}\left(r_{\mathrm{g}}=\right.$ $0.86)$ and the combination bands of $\mathrm{C}-\mathrm{H}$ stretch and deformations at $2310 \mathrm{~nm}\left(r_{\mathrm{g}}=0.94\right)$ and $2350 \mathrm{~nm}\left(r_{\mathrm{g}}=\right.$ $0.90)$. The spectral regions associated with water content had genetic and phenotypic correlations between

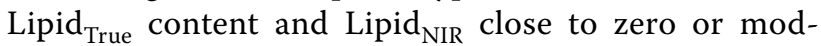
erately negative in sign, such as the $\mathrm{O}-\mathrm{H}$ overtone at $1450 \mathrm{~nm}\left(r_{\mathrm{g}}=-0.26\right.$ and $\left.r_{\mathrm{p}}=-0.05\right)$, the $\mathrm{O}-\mathrm{H}$ stretch at $1930 \mathrm{~nm}\left(r_{\mathrm{g}}=-0.61\right.$ and $\left.r_{\mathrm{p}}=-0.46\right)$ and the $\mathrm{O}-\mathrm{H}$ deformation at $1190 \mathrm{~nm}\left(r_{\mathrm{g}}=-0.37\right.$ and $\mathrm{r}_{\mathrm{p}}=$ -0.29 ). The correlations for the cis unsaturation combinations at $2140 \mathrm{~nm}$ and $2180 \mathrm{~nm}$ were weak for both the genetic (0.27-0.46) and phenotypic (0.15-0.32) correlations (see Additional file 6: Table S6 for NIR wavelength correlations).

\section{Discussion}

The heritable landscape of Raman and NIR vibrational spectra

To our knowledge, this is the first study that directly estimates the heritability of Raman and NIR vibrational spectra in muscle tissue. Remarkably, both Raman and NIR spectral landscapes contained bands for which the estimated heritability was quite high, i.e. bands with known associations with chemical bonds and functional groups. For instance, 827 individual Raman shifts had significant heritabilites $h^{2}$ that ranged from 0.15 to 0.65 , and the majority of these are in regions of fundamental stretching and deformation models that belong to covalent carbon to carbon, oxygen and hydrogen bonds present in lipids [25]. Similarly, 407 NIR wavelengths had significant heritabilities that ranged from 0.27 to 0.40 and were in regions associated with oxygen to hydrogen, carbon to hydrogen and carbon to carbon bonds [32]. 


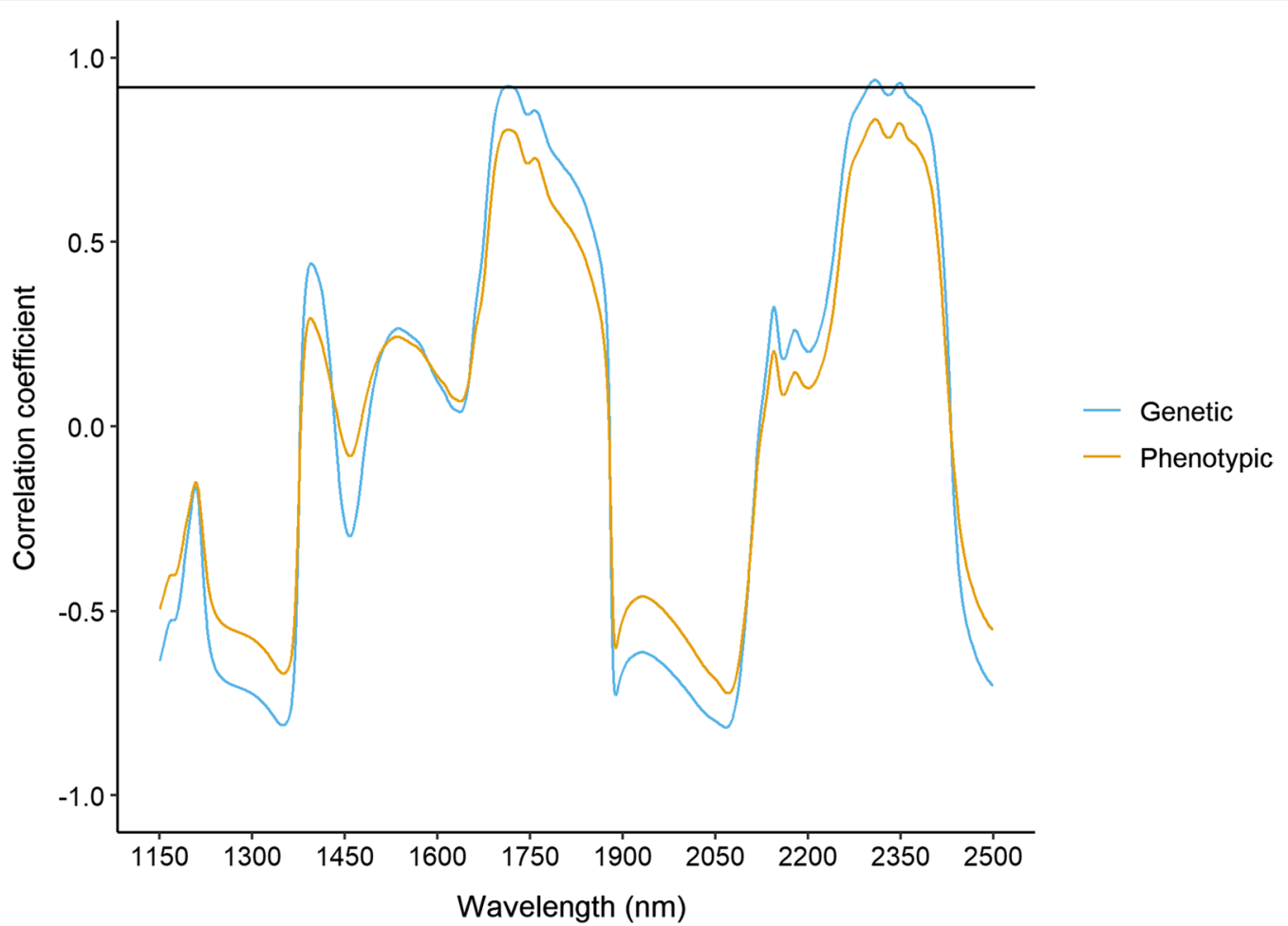

Fig. 4 Genetic (light blue) and phenotypic (yellow) correlations between each NIR wavelength and lipid content. The genetic correlation between NIR predicted lipid content and true lipid content indicated by the solid black line

The heritability estimates reported here are comparable or higher than those for mid-Fourier transform infrared spectra (FTIR), which are already used for routine genetic evaluations in the milk of dairy goats $\left(h^{2}=0.14-\right.$ 0.28) [34] and of multiple dairy cow populations $\left(h^{2}=\right.$ 0.01-0.63) [35-37]. Since Raman and NIR spectroscopic measurements are generally regarded as complementary techniques, and are well adapted to rapid and online measurements, finding significantly heritable regions from both methods holds promise for routine genetic evaluations in Atlantic salmon and other aquaculture species and warrants further investigation in muscle tissues of terrestrial livestock.

\section{Phenotyping lipid content}

Accurate phenotypes are a prerequisite for accurate breeding values. Using alternative methods for phenotyping lipid content in Atlantic salmon has been an active field of research since the publication of the first pioneering works using NIR and computerised X-ray tomography in salmonids $[16,39,40]$. However, phenotyping lipid content has value to producers beyond breeding practices, e.g., as response variables to treatments in experiments and management interventions as well as grading and pricing of whole fish or fillets under commercial conditions. Different scopes of application will have different requirements for accuracy, precision and correlation values, and in method agreement studies, it is common practice to estimate agreement indices which combine all three sources of (dis)agreement into a single statistic for comparisons [40]. We assessed overall agreement by Lin's concordance correlation coefficient (CCC), which penalises the Pearson's correlation coefficient for differences in variances (precision) and means (accuracy) between two methods [41]. We found high CCC for $\operatorname{Lipid}_{\text {Raman }}(C C C=0.92)$, followed by Lipid $(C C C=0.68)$ and $\operatorname{Lipid}_{\text {FieldNIR }}$ with $(C C C=0.62)$ which were both moderately high. In applications for which rapid and non-destructive measurements on fillets are needed, a producer might be willing to forgo some accuracy and precision to achieve this in practice, and the agreement between alternative methods and the reference method enables this. For instance, the two methods with the highest CCC were Lipid ${ }_{\text {Raman }}$ and Lipid but they were conducted on homogenised samples in the laboratory. Whereas CCC was lower for Lipid ${ }_{\text {FieldNIR, it }}$ is currently the only rapid and non-destructive commercially available solution. For small-scale experiments, for which accuracy and precision are required, it is still recommended to use the reference method or the reference 
method in combination with NIR or Raman spectroscopy. Currently, promising new instrumental developments are being reported for rapid measurement of lipid content on live fish with both Raman and NIR spectroscopy, which may result in alternative commercial solutions in the future $[14,42]$. For NIR, this is related to the so-called interactance principle, an optical configuration that allows photons that have travelled deeper into biological tissues to be collected [14]. For Raman, a similar approach, termed spatially-offset Raman spectroscopy, is currently being explored [42].

From a genetic evaluation perspective, the genetic parameters such as estimates of heritability and genetic correlations between alternative methods and the reference method are needed to inform the choice of method. However, genetic correlations between true lipid content and NIR predicted lipid content have not been reported to date. The best predictor of a phenotype is not necessarily the best predictor of genetic merit for the 'true' trait [37]. If non-genetic factors or residual correlations are driving the phenotypic prediction, it is possible that selecting on a predicted phenotype could yield poor or even undesired responses to selection. This is best illustrated with the FTIR prediction of stearic acid (C18:0), which is a fatty acid in the milk of dairy cows with a coefficient of determination $\mathrm{R}^{2}$ of 0.80 that indicates that predicting this phenotype is feasible. However, the genetic correlation estimated between the reference method and C18:0 predicted with FTIR was highly negative -0.86 [43]. If selection had been implemented based on the predicted C18:0 without knowledge of this negative genetic correlation, the response to selection in the true C18:0 would likely have been in the opposite direction than intended. Clearly, this highlights the value of validating the genetic correlations between true phenotype and predicted phenotype prior to genetic selection. The genetic correlations between alternative methods and the reference methods reported here were very high and close to $1\left(r_{g}=0.93-0.98\right)$ with high heritability estimates $\left(\mathrm{h}^{2}=0.52-0.67\right)$, which indicates that almost all the genetic variation in Lipid $_{\text {True }}$ is captured by the alternative methods. The threshold for genetic correlations between alternative and reference methods, which is called the "break-even correlation", is traditionally set at $0.70-0.80[45,46]$. Alternative methods with genetic correlations to the reference method below this threshold can be regarded as indicator traits and not genetically equivalent to the reference method, whereas methods that exceed this threshold can be used in direct genetic evaluations. The distinction is rather subtle, but it has implications for how traits are incorporated into the selection index as either the direct trait or an indicator trait, and it affects the genetic gain in the direct trait and the costs of phenotyping. In our study, the genetic correlations between the three alternative methods and the reference method $\left(r_{g}=0.93-0.98\right)$ are high and close to 1. As a further validation, we assessed the phenotypic and genetic correlations between Lipid ${ }_{T r u e}$ and individual Raman shifts and NIR wavelengths. The phenotypic and genetic correlations for both methods were nearly equivalent in both sign and magnitude. Furthermore, some spectral regions associated with chemical bonds found in lipids in Atlantic salmon had genetic correlations with Lipid $_{\text {True }}$ higher than 0.80 . Based on these findings, it is reasonable to conclude that vibrational spectroscopic methods in the field or the laboratory are nearly equivalent to the reference method and can be used in genetic selection programmes for fillet lipid content, provided the calibration equations based on the reference methods are accurately estimated.

\section{Raman and NIR vibrational spectroscopy beyond selection for lipid content}

Raman and NIR vibrational spectroscopy are able to detect relative amounts of numerous biochemical molecular bonds, and this offers possibilities for new phenotypes other than lipid content. It is already well established that NIR and Raman spectroscopy can be used to predict carotenoid content (astaxanthin and canthaxanthin) in the salmon fillet, which is responsible for the characteristic pink colour and is an important quality characteristic [14, 21]. Studies have even reported that the heritability of NIR-predicted canthaxanthin content is significant and ranged from 0.07 to 0.29 in Atlantic salmon fillets [13, 47]. Furthermore, Raman spectroscopy has been reported for the detection of aromatic amino acids content such as phenylalanine, tryptophan, histidine and tyrosine [47]. The most promising application is the partitioning of total lipid content into detailed fatty acids content. Health associated omega-3 fatty acids such as eicosapentaenoic and docosahexaenoic acids have been reported as significantly heritable in Atlantic salmon $\left(h^{2}=0.23\right.$ and 0.46 , respectively) [13]. Prediction of the fatty acid composition of Atlantic salmon fillet using NIR and Raman spectroscopy is an active field of research [25]. Further research is needed to assess the phenotypic scope of Raman and NIR vibrational spectroscopy in modern high-throughput breeding programmes.

As the use of rapid online vibrational spectroscopy gains traction for phenotyping in modern breeding programmes, another avenue of research is to reconcile at which level (phenotypic or genetic) the vibrational spectra are dimensionally reduced and the partial least squares predictions made. This is because even the largest breeding programmes in the world cannot phenotype 
a sufficient number of individuals necessary to estimate variance components and EBV in multi-trait mixed models for thousands of individual NIR wavelengths or Raman shifts. For instance, in dairy cattle and goats, the vibrational spectra are reduced to latent variables at the phenotypic level and used in PLSR to predict the phenotypes of interest. Then, in a second step, the predicted phenotypes are analysed in univariate mixed models to estimate EBV, which is termed indirect prediction [34]. An alternative approach is to reduce the vibrational spectra to latent variables and estimate variance components and EBV on the latent variables directly in a multi-trait mixed model, termed direct prediction [34]. Direct prediction has been reported to increase the reliability of EBV and reduce error variance in some applications but indirect prediction is the most common model in routine genetic evaluations. Although further research is needed to evaluate the factors that govern optimal use of direct or indirect predictions, the heritability estimates obtained in our study for individual NIR and Raman spectral landscapes lay down the foundation for genetic evaluations using vibrational spectral in animal tissues.

\section{Conclusions}

Specific Raman shifts and NIR wavelengths in the vibrational spectral landscapes recorded on Atlantic salmon fillets were significantly heritable $(0.15-0.65)$. The concordance correlation coefficients (CCC) between Raman and NIR predicted fillet lipid contents and the values obtained with the reference method ranged from moderate (0.63) to high values $(0.90)$, which validates the use of the former as phenotypes. Furthermore, the genetic correlations of Raman and NIR predicted lipid contents with the values obtained with the reference method were close to unity $\left(r_{\mathrm{g}}=0.91-0.98\right)$ and thus can be used in genetic evaluations. Spectral regions in both Raman and NIR could be assigned to chemical bonds of known importance in lipids. Both Raman and NIR vibrational spectra hold promise for high-throughput phenotyping and genetic evaluation of lipid content in the muscle of Atlantic salmon.

\section{Supplementary Information}

The online version contains supplementary material available at https://doi. org/10.1186/s12711-021-00605-6.

Additional file 1: Table S1. Estimated variance components for each individual Raman shift

Additional file 2: Table S2. Estimated variance components for each individual NIR wavelength.

Additional file 3: Table S3.Estimated breeding values (EBV) for each individual Raman shift.

Additional file 4: Table S4. Estimated breeding values (EBV) for each individual NIR wavelength,
Additional file 5: Table S5. Estimated phenotypic and genetic correlations between each individual Raman shift and the reference lipid value.

Additional file 6: Table S6. Estimated phenotypic and genetic correlations between each individual NIR wavelength and the reference lipid value.

\section{Acknowledgements}

The authors would like to express their gratitude to Karen Wahlstrøm Sanden for the commercial NIR measurements, to Målfrid Tofteberg Bjerke for determining the reference value lipid contents, and to Bjørg Narum, Ulrike Böcker and Silje Basmoen for the Raman measurements.

\section{Authors' contributions}

SSH, AKS, BR, BH and NKA planned and designed the experiment. GFD performed the data analysis and writing of the manuscript. KRD curated and processed all spectral data. All authors participated in the interpretation of the results. All authors read and approved the final manuscript.

\section{Funding}

Norwegian Research Council (Grant No. NFR 244200, Genomics of omega-3 in Atlantic salmon).

\section{Availability of data and materials}

The datasets generated and analysed during the current study are contained within the additional files, the remaining commercially sensitive data are available on reasonable request from Benchmark Genetics Norway AS.

\section{Ethics approval and consent to participate}

The use of these production fish was performed in strict accordance with the Norwegian Animal Welfare Act of 19th of June 2009, in force from the 1st of January 2010. The study was based on post-mortem sampling of material from fish harvested from a commercial breeding program (SalmoBreed AS) for other purposes. The experimental plan was evaluated according to the Norwegian regulation for the use of animals in experiments (FOR-2015-0618-761, Forskrift om bruk av dyr i forsøk). The regulation states that activities related to non-experimental aquaculture activities are exempt from the regulation and that it is legal to collect samples from animals post-mortem without a specific license. Thus, the samples used in this study were collected in accordance with the Norwegian legislation for animal experiments.

\section{Consent for publication}

Not applicable.

\section{Competing interests}

The authors declare that Borghild Hillestad is currently employed by Benchmark Genetics Norway AS and that no conflicts of interest exist.

\section{Author details}

${ }^{1}$ Nofima, Norwegian Institute for Food, Fisheries and Aquaculture Research, NO-1433 Ås, Norway. ${ }^{2}$ Benchmark Genetics Norway AS, Sandviksboder 3A, NO-5035 Bergen, Norway.

Received: 5 August 2020 Accepted: 18 January 2021

Published online: 05 February 2021

References

1. Mørkøre T, Vallet JL, Cardinal M, Gomez-Guillen MC, Montero P, Torrissen $\mathrm{O}$, et al. Fat content and fillet shape of Atlantic salmon: Relevance for processing yield and quality of raw and smoked products. J Food Sci. 2001:66:1348-54.

2. Sigurgisladottir S, Torrissen $\mathrm{O}$, Lie $\varnothing$, Thomassen $M$, Hafsteinsson $\mathrm{H}$. Salmon quality: Methods to determine the quality parameters. Rev Fish Sci. 1997;5:223-52.

3. Rørå AMB, Kvåle A, Mørkøre T, Rørvik KA, Steien SH, Thomassen MS. Process yield, colour and sensory quality of smoked Atlantic salmon (Salmo salar) in relation to raw material characteristics. Food Res Int. 1998;31:601-9. 
4. Janhunen M, Nousiainen A, Koskinen H, Vehviläinen H, Kause A. Selection strategies for controlling muscle lipid content recorded with a nondestructive method in European whitefish Coregonus lavaretus. Aquaculture. 2017:481:229-38.

5. Torstensen BE, Frøyland L, Lie O. Replacing dietary fish oil with increasing levels of rapeseed oil and olive oil - Effects on Atlantic salmon (Salmo salar L) tissue and lipoprotein lipid composition and lipogenic enzyme activities. Aquac Nutr. 2004;10:175-92.

6. Rye M, Gjerde B. Phenotypic and genetic parameters of body composition traits and flesh colour in Atlantic salmon Salmo salar L. Aquac Res. 1996;27:121-33.

7. Quinton CD, McMillan I, Glebe BD. Development of an Atlantic salmon (Salmo salar) genetic improvement program: Genetic parameters of harvest body weight and carcass quality traits estimated with animal models. Aquaculture. 2005;247:211-7.

8. Powell J, White I, Guy D, Brotherstone S. Genetic parameters of production traits in Atlantic salmon (Salmo salar). Aquaculture. 2008;274:225-31.

9. Janssen $\mathrm{K}$, Chavanne H, Berentsen P, Komen H. Impact of selective breeding on European aquaculture. Aquaculture. 2017:472:8-16.

10. Hazel LN. The genetic basis for constructing selection indexes. Genetics. 1943:28:476-90

11. Quinton CD, Kause A, Koskela J, Ritola O. Breeding salmonids for feed efficiency in current fishmeal and future plant-based diet environments. Genet Sel Evol. 2009:39:431-46.

12. Folch J, Lees M, Sloane SG. A simple methof for the isolation and purification of total lipides from animal tissues. J Biol Chem. 1957;226:497-509.

13. Horn SS, Ruyter B, Meuwissen THE, Hillestad B, Sonesson AK. Genetic effects of fatty acid composition in muscle of Atlantic salmon. Genet Sel Evol. 2018;50:23.

14. Folkestad A, Wold JP, Rørvik KA, Tschudi J, Haugholt KH, Kolstad K, et al. Rapid and non-invasive measurements of fat and pigment concentrations in live and slaughtered Atlantic salmon (Salmo salar L.). Aquaculture. 2008:280:129-35.

15. Veliyulin E, Van Der Zwaag C, BurkW, Erikson U. In vivo determination of fat content in Atlantic salmon (Salmo salar) with a mobile NMR spectrometer. J Sci Food Agric. 2005;85:1299-304.

16. Rye M. Prediction of carcass composition in Atlantic salmon by computerized tomography. Aquaculture. 1991;99:35-48.

17. Segtnan VH, Høy M, Sørheim O, Kohler A, Lundby F, Wold JP, et al. Noncontact salt and fat distributional analysis in salted and smoked salmon fillets using $x$-ray computed tomography and nir interactance imaging. J Agric Food Chem. 2009:57:1705-10.

18. Wold JP, Isaksson T. Non-destructive determination of fat and moisture in whole Atlantic salmon by near-infrared diffuse spectroscopy. J Food Sci. 1997;62:734-6.

19. Wubshet SG, Wold JP, Böcker U, Sanden KW, Afseth NK. Raman spectroscopy for quantification of residual calcium and total ash in mechanically deboned chicken meat. Food Control. 2019;95:267-73.

20. Tao F, Ngadi M. Recent advances in rapid and nondestructive determination of fat content and fatty acids composition of muscle foods. Crit Rev Food Sci Nutr. 2018;58:1565-93.

21. Wold JP, Marquardt BJ, Dable BK, Robb D, Hatlen B. Rapid quantification of carotenoids and fat in atlantic salmon (Salmo salar L.) by Raman spectroscopy and chemometrics. Appl Spectrosc. 2004;58:395-403.

22. Horn SS, Sonesson AK, Krasnov A, Moghadam H, Hillestad B, Meuwissen THE, et al. Individual differences in EPA and DHA content of Atlantic salmon are associated with gene expression of key metabolic processes. Sci Rep. 2019;9:3889.

23. Wold JP, Bjerke F, Måge I. Automatic control of fat content in multiple batches of meat trimmings by process analytical technology. Fleischwirtschaft Int. 2016;31:69-74.

24. Liland KH, Kohler A, Afseth NK. Model-based pre-processing in Raman spectroscopy of biological samples. J Raman Spectrosc. 2016;47:643-50.

25. Afseth NK, Segtnan VH, Marquardt BJ, Wold JP. Raman and near-infrared spectroscopy for quantification of fat composition in a complex food model system. Appl Spectrosc. 2005;59:1324-32.

26. Mevik B-H, Wehrens R. Introduction to the pls Package. Packag. RStudio Softw. 2015. https://mran.microsoft.com/snapshot/2016-10-05/web/packages/pls/ vignettes/pls-manual.pdf. Accessed 20 December 2020.

27. Lin LI. A concordance correlation coefficient to evaluate reproducibility. Biometrics. 1989:45:255-68.

28. Madsen P, Jensen J. A user's guide to DMU, version 6, release 5.0. 2013. https ://dmu.ghpc.au.dk/DMU/Doc/Current/dmuv6_guide.5.2.pdf/Accessed 20 December 2020.
29. Benjamini Y, Hochberg Y. Controlling the false discovery rate: a practical and powerful approach to multiple testing. J R Stat Soc B. 1995;57:289-300.

30. Calo LL, McDowell RE, VanVleck LD, Miller PD. Genetic aspects of beef production among Holstein-Friesians pedigree selected for milk production. J Anim Sci. 1973;37:676-82.

31. Blanchard PJ, Everett RW, Searle SR. Estimation of genetic trends and correlations for Jersey cattle. J Dairy Sci. 1983;66:1947-54.

32. Afseth NK, Wold JP, Segtnan VH. The potential of Raman spectroscopy for characterisation of the fatty acid unsaturation of salmon. Anal Chim Acta. 2006;572:85-92.

33. Czamara K, Majzner K, Pacia MZ, Kochan K, Kaczor A, Baranska M. Raman spectroscopy of lipids: A review. J Raman Spectrosc. 2015;46:4-20.

34. Dagnachew BS, Kohler A, Ådnøy T. Genetic and environmental information in goat milk Fourier transform infrared spectra. J Dairy Sci. 2013;96:3973-85.

35. Wang Q, Hulzebosch A, Bovenhuis H. Genetic and environmental variation in bovine milk infrared spectra. J Dairy Sci. 2016;99:6793-803.

36. Zaalberg RM, Shetty N, Janss L, Buitenhuis AJ. Genetic analysis of Fourier transform infrared milk spectra in Danish Holstein and Danish Jersey. J Dairy Sci. 2019;102:503-10

37. Rovere G, de los Campos G, Tempelman R, Vazquez Al, Miglior F, Schenkel $F$, et al. A landscape of the heritability of Fourier-transform infrared spectral wavelengths of milk samples by parity and lactation stage in Holstein cows. J Dairy Sci. 2019;102:1354-63.

38. Gjerde B, Martens H. Predicting carcass composition of rainbow trout by nearinfrared reflectance spectroscopy. J Anim Breed Genet. 1987;104:137-48.

39. Gjerde B, Gjedrem T. Estimates of phenotypic and genetic parameters for carcass quality traits in rainbow trout. Aquaculture. 1984;36:97-110.

40. Barnhart HX, Haber MJ, Lin LI. An overview on assessing agreement with continuous measurements. J Biopharm Stat. 2007;17:529-69.

41. Barnhart HX, Lokhnygina Y, Kosinski AS, Haber M. Comparison of concordance correlation coefficient and coefficient of individual agreement in assessing agreement. J Biopharm Stat. 2007;17:721-38.

42. Afseth NK, Bloomfield M, Wold JP, Matousek P. A novel approach for subsurface through-skin analysis of salmon using spatially offset raman spectroscopy (sors). Appl Spectrosc. 2014;68:255-62.

43. Poulsen NA, Eskildsen CEA, Skov T, Larsen LB, Buitenhuis AJ. Comparison of genetic parameters estimation of fatty acids from gas chromatography and FT-IR in Holsteins. In Proceedings of the 10th World Congress of Genetics Applied to Livestock Production: 17-22 August 2014; Vancouver. 2014.

44. Robertson $A$. The sampling variance of the genetic correlation coefficient. Biometrics. 1959;15:469-85.

45. Mulder HA, Veerkamp RF, Ducro BJ, Van Arendonk JAM, Bijma P. Optimization of dairy cattle breeding programs for different environments with genotype by environment interaction. J Dairy Sci. 2006;89:1740-52.

46. Norris AT, Cunningham EP. Estimates of phenotypic and genetic parameters for flesh colour traits in farmed Atlantic salmon based on multiple trait animal model. Livest Prod Sci. 2004;89:209-22

47. Madzharova F, Heiner Z, Kneipp J. Surface enhanced hyper-Raman scattering of the amino acids tryptophan, histidine, phenylalanine, and tyrosine. J Phys Chem C. 2017;121:1235-42.

48. Vieira VLA, Norris A, Johnston IA. Heritability of fibre number and size parameters and their genetic relationship to flesh quality traits in Atlantic salmon (Salmo salar L.). Aquaculture. 2007:272:S100-9.

49. Glover KA, Otterå H, Olsen RE, Slinde E, Taranger GL, Skaala Ø. A comparison of farmed, wild and hybrid Atlantic salmon (Salmo salar L.) reared under farming conditions. Aquaculture. 2009;286:203-10.

50. Sodeland M, Gaarder M, Moen T, Thomassen M, Kjøglum S, Kent M, et al. Genome-wide association testing reveals quantitative trait loci for fillet texture and fat content in Atlantic salmon. Aquaculture. 2013;408-409:169-74.

51. Tsai HY, Hamilton A, Guy DR, Tinch AE, Bishop SC, Houston RD. The genetic architecture of growth and fillet traits in farmed Atlantic salmon (Salmo salar). BMC Genet. 2015;16:51.

52. Sapkota J. Grading of correlated quality traits for added market value in Atlantic salmon (Salmo salar L.) - A model with example data. Master thesis, Norwegian University of Life Sciences; 2010.

\section{Publisher's Note}

Springer Nature remains neutral with regard to jurisdictional claims in published maps and institutional affiliations. 